\title{
ORIGEN DEL COLEGIO DE JESUITAS DE ZARAGOZA
}

\author{
JOSE A. FERRER BENIMELI ${ }^{1}$
}

\begin{abstract}
RESUMEN: Se inicia este estudio recordando el contexto histórico en el que Ignacio se mueve y sus relaciones con el mundo de la cultura y el universitario que inicialmente le llevan a no plantear la cuestión de los colegios. Será Laínez quien decida ponerlos en marcha. Tras la experiencia de los primeros implantados en India, España e Italia se analiza el origen y vicisitudes fundacionales (económicas, sociológicas, religiosas y políticas) del colegio de Zaragoza, el más importante de los nueve que existieron en Aragón propiamente dicho antes de la expulsión de Carlos III, si bien eran 28 los establecidos en la entonces provincia jesuítica de Aragón, identificada de hecho con la antigua Corona de Aragón.
\end{abstract}

Palabras clave: Jesuitas; Colegios; Aragón; Zaragoza; Borja.

\section{Origin of the Jesuits College in Zaragoza}

ABSTRACT: This study begins remembering the historical context in which Ignacio develops as well as his relationships with the culture and academic context. Initially, he does not raise the question of schools. It will be Lainez who decides to establish them. After the experience of the first colleges founded in India, Spain and Italy, the origin and (economical, sociological, religious and political) groundwork vicissitudes of the school from Zaragoza are analyzed. It is the most important college from the nine that were created in Aragon before the expulsion by Charles III. There were 28 colleges established in the Jesuit province of Aragon, identified with the old Crown of Aragon.

KEY WORDS: Jesuits; Colleges; Aragón; Zaragoza; Borja.

Tres son los aspectos de la obra del P. Manuel Revuelta que quisiera destacar y que me han inspirado estas líneas: la restauración de la Compañía, los colegios de jesuitas, y Aragón. Tres lados de un triángulo académicoafectivo en el que resulta difícil establecer prioridades. Las consecuencias del extrañamiento, extinción y restauración de la Compañía de Jesús, supuso durante años un trabajo en común en el que yo me ocupaba de la expulsión y

\footnotetext{
1 Universidad de Zaragoza. Correo electrónico: bibliotecasalvadorzaragoza@ gmail.com.
} 
extinción y el P. Revuelta de la restauración. Fueron años en los que el estudio y la investigación trascendió al terreno del conocimiento mutuo y al de la amistad fraternal que fructificó en la presencia y colaboración en congresos internacionales como los de México (2013) y Bogotá (2014) organizados por las universidades pontificias Iberoamericana y Javeriana, y los de Salamanca (2014) y Comillas-ICAI (2015).

A estos se añadieron ciclos de conferencias y publicaciones conmemorativas del bicentenario de la restauración especialmente las realizadas por El Mensajero. Libros y trabajos de Revuelta definitivos en una temática bien conocida por él y mejor expresada con su estilo sobrio pero lleno de sabiduría y conocimiento.

La cuestión de los colegios de jesuitas y su tradición educativa fue otra de las preocupaciones académicas e investigadoras del P. Revuelta de la que dio cumplida cuenta en su excelente obra publicada en la Universidad Pontificia Comillas el año 1998 así como el breve, pero igual de enjundioso estudio titulado La Compañía de Jesús en Aragón hace cien años (Revuelta, González, 2001).

De estas tres vías de investigación histórica, la primera, la de la restauración y la previa extinción, fue la más estudiada en recíproca colaboración y la que nos permitió participar en intercambios y planteamientos historiográficos durante conversaciones, viajes y estudios, especialmente en Madrid, Ciudad de México y Bogotá, donde llegué a mejor conocer y apreciar no tanto al Revuelta historiador e investigador — que ya lo era — sino al Revuelta humano, sensible y cordial que intentaba sin éxito ocultar bajo su capa de castellano profundo.

A él van dirigidas estas líneas sobre los difíciles orígenes del colegio de jesuitas de Zaragoza en homenaje al maestro, hermano y amigo que supo transmitir su interés por tantos temas que acabaron siéndonos comunes.

En 1491 cuando nace Iñigo de Loyola el mundo europeo atravesaba una severa crisis —que nos recuerda a la actual—. Crisis económica, política, institucional, social, religiosa y cultural educacional. La crisis afectaba también al mundo del saber.

Hoy empezamos a ser conscientes de la importancia y gravedad de las crisis económicas y político-institucionales. Pero tal vez no lo somos todavía de que una crisis cultural-educacional puede revelarse en términos tan peligrosos para la sociedad como una crisis política o económico-financiera. La cultura y educación no es un lujo del estado de bienestar o de una sociedad en abundancia. Es un bien tan importante como las materias primas, el dinero o el poder. Los instrumentos culturales-educacionales son tan vitales para la sociedad como los instrumentos políticos, jurídicos o financieros. No 
olvidemos que la pedagogía revela las estructuras de la sociedad y transforma al mismo tiempo la sociedad en la que es aplicada.

En la época de Iñigo de Loyola las escuelas tradicionales se vieron confrontadas a nuevas exigencias. El mundo antiguo estaba en plena crisis. Era —en palabras de Huizinga - el otoño de la Edad Media.

Pero al lado de este mundo en crisis emerge una nueva sociedad. Artesanos y burgueses de las ciudades prosperan y reclaman el poder político y exigen participar en la cultura. Este florecer del Renacimiento es esencialmente mantenido por laicos urbanos y ya no por monjes.

El saber experimenta su propia revolución copernicana. En pocos años, el mundo medieval cede el sitio al mundo del Renacimiento. Lo que cambia es la relación fundamental entre el conocimiento, la cultura y la ciencia.

Para el ilustrado de la Edad Media lo que cuenta no es la observación sino el comentario. La validez de una teoría no reposa en la verificación experimental, ni siquiera en su hipotética falsedad, sino sobre la autoridad del autor. Lo que cuenta no es el mundo observado por Ptolomeo, sino lo que Ptolomeo dice de él. En consecuencia, el escolástico culto privilegia la repetición al comentario y la glosa.

Para el ilustrado humanista el objeto del conocimiento ha cambiado. En lugar de la autoridad del autor, es la autoridad del texto lo que hay que buscar. Para el gramático, es el texto de Homero o de Cicerón; para el filósofo es el texto de Aristóteles o de Platón; para el teólogo, es el texto de la Biblia o de los Padres de la Iglesia. Para el que investiga la naturaleza, la observación del mundo reemplaza el comentario del autor.

Para el estudioso de la Edad Media, el texto era raro y en consecuencia sagrado. Toda la pedagogía medieval está fundada en la lectura de textos; y la escolástica universitaria «institucionaliza» y amplifica este tipo de trabajos. La enseñanza estaba esencialmente basada sobre la lectio, la lectura; privilegiaba la transmisión oral en un mundo todavía profundamente analfabeto.

Para el estudioso del Renacimiento, el mundo se convierte en un gigantesco texto. Se trata de descifrarlo y no de repetirlo. Por eso al aprendizaje mnemotécnico de fórmulas, sucede la lectura silenciosa, la reflexión, la exégesis, pero también la praelectio, método que combina la explicación, el análisis y la síntesis bajo la forma de diálogo, de ejercicios, de repeticiones.

El humanismo es, pues:

1) Un método de investigación que se caracteriza por una primacía de la exégesis que supone explicación, exposición y sobre todo comentario crítico.

2) El humanismo desplaza el centro de gravedad de la especulación sobre lo divino hacia el estudio de la condición humana. Prima la 
antropología sobre el teocentrismo. El humanismo es una disposición de espíritu filosófico.

3) El humanismo pone en valor la observación de los fenómenos humanos y naturales. Lo humano científico.

4) El humanismo revaloriza la gramática y los autores antiguos y constituye los estudios literarios.

5) El humanismo representa corrientes en evolución. Los primeros humanistas italianos eran «coleccionistas» de manuscritos y antigüedades que resucitan el mundo latino y griego.

En este contexto Ignacio de Loyola todavía no pertenece al mundo que cambia (o al «mundo nuevo»). Apenas es diferente de Rabelais, Erasmo, Lutero, Calvino o Tomás Moro. Ni siquiera es diferente a Cristóbal Colón el aventurero o a las pobres "brujas" víctimas de la hoguera. Podríamos decir que participa de sus utopías, de su melancolía, su rigor, sus fidelidades o de su locura...

Ignacio es el típico representante de la pequeña nobleza campesina, destinado a la milicia. Su formación se limita a escribir en castellano y a leer novelas de caballerías en la corte de Arévalo, en Castilla. A raíz de ser herido en 1521 en el asedio de Pamplona, experimenta una ruptura cultural y espiritual, como la de tantos hombres de su época: el propio Erasmo, o Rabelais, Lutero... Y a los 34 años decide ampliar sus conocimientos; abandona el barniz «cultural» de la nobleza y entra en el mundo de la gramática. Comienza entonces un itinerario intelectual que explica en parte la posición que adoptará frente a la cultura de su tiempo. Entre 1524 y 1534, fecha de los votos hechos en Montmatre por un grupo de universitarios y germen de lo que luego será la Compañía de Jesús, Ignacio tiene ocasión de encontrarse con las diferentes corrientes que agitan el mundo intelectual cristiano.

En 1524 estudia gramática en Barcelona, bajo la dirección de Jerónimo Ardevol, maestro pagado por la ciudad. Y allí experimenta las dificultades de estudiar —a sus 33 años— entre niños, según los métodos clásicos de las escuelas urbanas.

En 1526 va a Alcalá, cuya Universidad moderna está abierta al humanismo especialmente por la enseñanza del latín, griego y hebreo. Allí estudia filosofía y teología enseñadas según el método escolástico clásico. Es acusado ante la Inquisición de ser sospechoso de iluministo y erasmismo. Marcha a Salamanca, donde encuentra nuevas dificultades con la Inquisición, siendo encarcelado en el convento de los dominicos. Al recobrar la libertad decide ir a París para estudiar en la Sorbona. 
De 1528 a 1534 recomienza su cursus: gramática, filosofía y teología. En el Colegio de Monteagudo vuelve al estudio de la gramática latina. Este colegio, en el que habían estudiado Erasmo y Rabelais, era un lugar pionero entre la enseñanza medieval y los nuevos métodos humanistas. En el Colegio de Santa Bárbara completa su formación con el bachillerato, licencia y maestría en artes. Este colegio era punto de reunión de los humanistas. Se enseñaba Aristóteles, la Escritura y los Padres de la Iglesia. En el Colegio de Santiago comienza sus estudios de teología bajo la dirección de los dominicos. Finalmente, en 1535, concluye su periplo de formación en las Universidades de Bolonia y Venecia donde conoció los modelos de enseñanza italianos.

Cuando Ignacio termina sus estudios ni siquiera pensaba en crear una orden religiosa, ni mucho menos en fundar una orden dedicada a la enseñanza. Deseaba solamente con sus compañeros universitarios de París (Laínez, Salmerón, Fabro, Francisco Javier... $)^{2}$ ir de peregrinación a Jerusalén. Más aún, cuando en 1540 funda la Compañía de Jesús, aprobada por el Papa Pablo III, la cuestión de los colegios no se planteó. Sin embargo, a raíz de la entrada en la Compañía de jóvenes que todavía no habían concluido sus estudios superiores de Artes y Teología, Ignacio de Loyola, por iniciativa de Laínez, decidió poner en marcha colegios, aunque solamente residenciales destinados a jóvenes universitarios que se incorporaban a la Compañía. Quería formarlos lo mejor posible y decidió enviarlos a las más acreditadas universidades. Vivían en comunidad, pero dentro de casa no se explicaba asignatura alguna. Acudían a la universidad para las clases. En 1541 se fundó en París el primer centro o colegio-residencia ${ }^{4}$. Al año siguiente se constituyeron los de Coimbra, Padua y Lovaina. Siguieron muy pronto los de Valencia y Colonia (1544), Valladolid (1545), Alcalá y Barcelona (1546) y Salamanca (1547).

Los escolares jesuitas fueron desde el principio unos universitarios en el sentido pleno de la palabra, como lo habían sido Ignacio y los primeros compañeros. Procuraron asimilar la cultura universitaria y familiarizarse con la mentalidad y los métodos que se practicaban en los mejores centros de Europa ${ }^{5}$.

2 Diego Laínez, Alfonso Salmerón, Pedro Fabro, Francisco Javier, Simón Rodríguez, Nicolás Bobadilla.

3 Paulo III aprobó la Compañía de Jesús el 27 de septiembre de 1540 por la bula Regimini militaris Ecclesiae.

${ }_{4}$ Los primeros colegios de jesuitas no fueron, pues, centros de educación, sino lo que hoy llamamos Colegios Mayores o Colegios Menores.

5 Esta vocación universitaria encuentra sus raíces en el origen de los fundadores de la Compañía, todos ellos graduados por la Universidad de la Sorbona de París donde se gestó el germen de lo que acabaría siendo la Compañía de Jesús. Iparraguire (1962). 
Fue entonces cuando Ignacio organizó la formación de los jesuitas que luego se aplicaría a los estudiantes no jesuitas. Y ante la necesidad de elegir entre los antiguos y los modernos optó por realizar una síntesis pedagógica entre la enseñanza medieval y el humanismo literario. Y para ello se basó en lo adquirido durante sus propios estudios, especialmente los de París. Tanto Ignacio, como sus otros compañeros, prefirieron aplicar el método de estudios de la Sorbona al que llamaron el "modus parisiensis", que tenía como base, la unidad, jerarquía, división y gradación de las clases y programas. Es decir, un método didáctico y eficaz.

Pero debido a la penuria económica, la mayor parte de estos primeros colegios-residencia no pasaron de ser proyectos fracasados pues apenas encontraron fundadores para costearlos. Y ante la dificultad que suponía ponerlos en marcha ya que en ellos sólo se formaban jesuitas, hubo obispos que pusieron como condición que se admitieran también a estudiantes de sus diócesis. Así se hizo añadiendo entre los miembros de los colegios a los preceptores encargados de ayudar y dar cursos que sirvieran de complemento a los que recibían en la Universidad, tanto los estudiantes residentes como los externos que desearan aprovecharse de estos cursos.

Este fue el origen de los primeros colegios de enseñanza de la Compañía, el de Goa en la India, Gandía en España, y Messina y Roma en Italia, fundados respectivamente en 1544, 1545, 1548 y 1551.

En Goa, Francisco Javier, al poco de llegar, recibió del Gobernador el ofrecimiento de hacerse cargo del colegio más importante que allí se había fundado hacía pocos años por unos seglares cristianos. Fue el primer colegio de los jesuitas en el mundo. El colegio de San Pablo, de Goa, llegaría a ser una de las principales universidades de la India.

En Europa, el duque de Gandía, Francisco de Borja, amigo de la recién nacida Compañía - y futuro jesuita y tercer General de la misma- quiso implantar en su ciudad un colegio destinado a convertirse en universidad, rango que Carlos V y el papa Paulo III le concedieron más tarde. Finalmente, el modelo de Goa y Gandía se perfeccionó cuando la comuna de Messina, a sugerencia del entonces virrey de Sicilia don Juan de Vega (y futuro Presidente del Consejo de Castilla en 1557), pidió a los jesuitas la fundación de un colegio para los jóvenes de la ciudad.

Precisamente para este colegio, Jerónimo Nadal escribió una especie de constitución que acabó aplicándose a todos los colegios de jesuitas: la conocida como Ratio studiorum o método de enseñanza que en su versión acabada de 1599 es una síntesis de la pedagogía que se aplicó en los colegios de 
jesuitas ${ }^{6}$. Pedagogía que miraba más a formar las cabezas que a llenarlas. El latín ocupaba un lugar privilegiado pues el ejercicio de la traducción servía para perfeccionar la lengua materna. En las clases era básica la «prelección» de un texto escogido, que ayudaba a formar la inteligencia juntando el análisis y la síntesis, y presentando el contexto histórico. La actividad personal del alumno era despertada por medio de preguntas y tareas, y estimulada por la emulación individual y las «concertaciones» (privadas o públicas).

En el colegio de Gandía los jesuitas asumieron la enseñanza de todas las materias. En el acta de fundación se hace constar que el colegio se erige para la formación de los jesuitas a la vez que para los de fuera. Como señala Nadal en su Chronicon, en el colegio de Gandía «comienzan los jesuitas a enseñar públicamente» en España. Otro tanto ocurrió con el de Messina en Italia. En los documentos fundacionales de 1548 se habla de un colegio para jesuitas al que podrían asistir seglares. Pero en realidad se admitieron tantos alumnos seglares y tan pocos escolares jesuitas, que en el contrato estipulado a los dos años, 1550, se habla sólo de los seglares. En 1555 había ya 275 escolares seglares, frente a un sólo escolar jesuita.

El colegio Romano quiso Loyola que fuera el colegio «piloto» de la Compañía y él mismo escribió de su propia mano los primeros Estatutos. Este colegio, hoy Universidad Gregoriana, acabó convirtiéndose en modelo de todos los demás.

A partir de este momento la Compañía se transformó en una Orden dedicada también a la enseñanza considerada como un nuevo apostolado: el literario y moral a través de los colegios. Pero hasta 1553 las Constituciones de la Orden no fueron adaptadas en este sentido por San Ignacio, y en particular la parte IV en la que se habla de los Colegios, es decir: «La educación de la juventud en general y la preparación de los nuevos jesuitas que deberían consagrarse a la enseñanza o a otros ministerios religiosos».

La finalidad y ventajas de estos colegios queda expresada gráficamente en la carta que el entonces provincial de España, Antonio de Araoz, dirigió a Ignacio de Loyola por esas fechas:

De los que solamente son al presente estudiantes, saldrán con el tiempo... quién para predicar y tener cura de ánimas, quién para el gobierno de la tierra y administración de la justicia, quien para otros cargos. Y finalmente porque de los niños se hacen los grandes, la buena educación en vida y doctrina de éstos,

6 Ratio atque Institutio Studiorum Societatis Iesu, Neapoli: Ex typographia Tarquini Longi MDCIII. Sobre las diferentes ediciones de la Ratio Studiorum, cfr. Gil, E. (ed.) (1992) y Labrador et. al. (1986). 
aprovechará a muchos extendiéndose cada día más el fruto (Bertán Quera, 1984, pp. 10-11).

En estos colegios destinados sobre todo a la juventud en general se enseñaba no solamente las Humanidades, sino también la lógica en materia de propedéutica. Lo que entonces se entendía por Humanidades o «letras de humanidad y lenguas» era: gramática, retórica, poesía e historia.

Para la gramática, como base indispensable para entrar más adelante en el estudio de las humanidades, se establecieron tres clases graduadas: clase primera o ínfima, clase segunda o media y clase tercera o suprema. El tercer curso de gramática solía corresponder al primer año de Colegio. En esta clase se enseñaba a los alumnos los principios de la gramática y los rudimentos y fórmulas para las declinaciones y conjugaciones que luego se aplicaban en los ejercicios prácticos. También se enseñaban las reglas de armonía y composición de pequeños temas fáciles en los que los estudiantes debían usar palabras corrientes. Los libros empleados en esta clase eran los rudimentos de la Gramática de Emmanuel Alvarez y cartas breves y escogidas de Cicerón ${ }^{7}$.

Muy pronto, pero especialmente en los siglos XVII y XVIII, algunos colegios dieron también una importancia muy particular a la enseñanza de materias no incluidas en los reglamentos oficiales de estudios, como las lenguas vernáculas, la literatura, la geografía, la arquitectura civil y militar, la geometría, la mecánica, la hidráulica, la agronomía, la economía o finanzas y el dibujo técnico, las matemáticas, la física y ciencias naturales o historia natural ${ }^{8}$.

7 Los textos más utilizados solían ser los del P. Emmanuel Alvarez, nacido en Ribeira Brava (isla de Madeira) en 1526. Fue rector de Coimbra y de Evora donde murió el 30 de diciembre de 1582. Y en especial De Arte retorice (1560) y De Institutione Grammatica que constaba de tres libros: I De Etymologia, II De Syntaxi, III De Prosodia. Esta gramática, publicada por primera vez en 1572, se convirtió en la obra clásica para la mayor parte de los colegios de la Compañía, y fue reconocida por la Ratio studiorum. De ella existen múltiples ediciones como recoge C. Sommervogel, Bibliothèque de la Compagnie de Jésus, Bruxelles, 1890, t. I, col. 223-249. Para el Collegium Santae Mariae Verolensis de Zaragoza, todavía se editó en 1927 con el título de Institutionum Grammaticarum (Barcinone, Subirana). Sobre los horarios y distribución de clases, así como de los textos utilizados, es de gran utilidad, porque da la pauta que se seguía en todos los colegios, la obra de Marquis (1969). También, Farrell (1937, pp. 287-291), Leturia (1940, pp. 350-382) y Leturia (1957, pp. 323-354).

8 Aunque en Europa se fue imponiendo el francés como lengua diplomática o internacional, en función de las sucesivas divisiones territoriales experimentadas - sobre todo en el centro y este de Europa - encontramos, por ejemplo, en la provincia jesuítica de Austria-Hungría, que en los colegios había profesores no sólo de francés, sino también de alemán, húngaro, italiano y checo (Ferrer Benimeli, 1984, pp. 329-360), (Dainville, 1978). 
Las clases se impartían de forma gratuita, sin excluir a ningún alumno «por no ser de condición elevada o por ser pobre» y cuidando del mismo modo «de los estudios de los pobres, que de los estudios de los ricos» (Luckacs, 1960, pp. 189-245; 1961, pp. 3-89). Sin embargo, la creencia común sigue siendo de que los colegios de jesuitas eran "de pago", lo cual no es cierto, al menos hasta la expulsión decretada por Carlos III en 1767 y la posterior extinción papal de 1773. La aceptación indiscriminada de los alumnos era preceptiva en la Ratio studiorum: «Neminem vero eo quod ignobilis aut pauper excludat». En el acuerdo de Mallorca se especifica «tingan obligació de enseñar en ellas continuament alls fills y naturals de esta Illa tant les pobres come les ricos...» (Bartolomé Martínez, 1982, p. 432). El Colegio Romano fundado por San Ignacio y prototipo de los que la Compañía fundó en todo el mundo, se abría el 22 de febrero de 1551 en una modesta casa sobre cuya puerta se podía leer la siguiente inscripción: «Escuela de Gramática, de Humanidades y Doctrina Cristiana, gratis» (Muñoz, 1960, pp. 203-244) ${ }^{9}$.

Desde el punto de vista financiero los colegios debían disponer de fondos y rentas sólidas para poder dispensar una enseñanza enteramente gratuita. Las rentas debían ser suficientes no sólo para las necesidades de los profesores y maestros de escuela, sino también para las de un cierto número de jesuitas que cursaban estudios para llegar a ser, también ellos, maestros de esos colegios.

Por esta razón, y en función del origen de sus fondos, los colegios adoptaron títulos y reglamentos diversos, según que el dinero fuera suministrado por el Papa, las autoridades comunales, particulares, obispos o príncipes soberanos. Así, hay que distinguir colegios de fundación papal (el colegio Romano), de fundación comunal (los colegios de Messina y Palermo en Sicilia), de fundación privada (el colegio universidad de Sassari en Cerdeña o los de Venecia y Padua), de fundación episcopal, y más tarde real (el colegio de Paris), de fundación imperial (el colegio de Madrid o el de Viena en Austria).

Además en cada una de las provincias jesuíticas había al menos un colegio con las Facultades de Artes y Teología. Fue el Papa Pío IV quien les dio, a partir de 1561, la autorización de conceder grados universitarios. Y al mismo tiempo hubo soberanos que confirieron también el título de Universidad a algunos Colegios superiores. Así, pues, en función de su vocación o finalidad se pueden distinguir tres clases de colegios de jesuitas: escuelas primarias, escuelas secundarias y escuelas superiores o universidades. A estos habría que añadir los llamados Colegios Mayores y los Colegios de Nobles

9 En 1627 de los 40.000 alumnos que se educaban en los colegios de Francia, más de la mitad eran hijos de artesanos, mercaderes y labriegos. Los hijos de nobles no llegaban al diez por ciento. 
(Olaechea, 1976, pp. 53-90) ${ }^{10}$. En sus orígenes hubo, pues, diferentes tipos de colegios que respondían a situaciones también diferentes. El collegium era un instrumento muy flexible que se adaptaba a las necesidades intelectuales y sociales de cada país y ciudad.

A la muerte de Ignacio de Loyola, en 1556 había ya repartidos por todo el mundo 45 colegios, incluido el fracasado colegio árabe en Sicilia cuya enseñanza se impartía en árabe con vistas a la evangelización de los países islámicos, y que se inició con tres niños árabes y dos jesuitas, uno natural de Trípoli y otro de Malta.

En 1606, apenas cuarenta y siete años después eran 93, de los que 38 estaban en América, India y Japón. Y en 1615 el mapa de los colegios de jesuitas —sólo en Europa- resulta bastante significativo, según el Atlas zur Kirchen Geschichte, de Hubert Jedin ${ }^{11}$.

Por lo que respecta a España, los jesuitas quedaron constituidos en 1546 en la provincia castellana, que unos años después, en 1552, fue dividida en provincia Ulterior o Castellana y provincia Citerior o Aragón. El Aragón jesuítico estaba integrado por Aragón y Cataluña -incluida Perpignan-, Baleares y Valencia. Y a partir de 1559 fue incorporada también Cerdeña. Es decir los territorios que en su día constituyeron gran parte de la Corona de Aragón. Además tenía adjudicada Filipinas y las llamadas misiones del Paraguay, más conocidas como guaraníes, que abarcaban no sólo el actual Paraguay y Uruguay, sino también Argentina y Chile.

En el momento de la expulsión decretada por Carlos III, en 1767, la provincia jesuítica de Aragón tenía 28 colegios de los que tan sólo nueve estaban en Aragón propiamente dicho, a saber: Caspe, dos en Calatayud, Graus, Huesca, Tarazona, Teruel y dos en Zaragoza. El resto se repartían diez por la actual Cataluña, a los que habría que añadir el de Perpignan y los cinco de la isla de Cerdeña, que también dependían de dicha provincia; los seis de Valencia y Alicante, y los tres de Mallorca ${ }^{12}$. En ultramar, los jesuitas de Aragón tenían a su cargo otros 30 colegios: 12 en Chile, 11 en Argentina y Paraguay, y 7 en Filipinas.

10 En España, en el siglo XVIII los jesuitas tenían seis Colegios Mayores. Cuatro en Salamanca: los colegios de San Bartolomé, Santiago, Cuenca y San Salvador; en Alcalá el de San Ildefonso, y en Valladolid, el de Santa Cruz. En la provincia jesuítica de Aragón hubo Colegios de Nobles en Calatayud, Valencia y Barcelona.

11 Publicado por Herder en Freiburg-Basel-Wien en 1970.

12 A saber: Alicante, Alghero, Barcelona, Cagliari, Cervera, Gandía, Gerona, Lérida, Mallorca (2), Manresa, Onteniente, Orihuela, Perpignan, Pollensa, Sassari, Tarragona, Tortosa, Urgel, Valencia (2), Vich. 
Los tres primeros colegios aragoneses de jesuitas se fundaron ya en el siglo XVI: Zaragoza en 1555, Calatayud en 1584 y Tarazona en 1591. Entre 1579 y 1605 hubo intentos de crear otros colegios en Belchite, Jaca, Alcañiz, Sos, Mas de las Matas y Cariñena. Aparte de estos proyectos fallidos, en el siglo XVII se establecieron el colegio de Huesca (1605), la residencia de Fonz (1635) — de corta vida - y los colegios de Graus (1656) y Teruel (1689), así como la residencia de Alagón (1688) destinada a convertirse en colegio y el colegio de Caspe (1750), éste último ya en pleno siglo XVIII.

La idea de establecer un colegio en Zaragoza se debió a Francisco de Borja (1510-1572) biznieto de Fernando el Católico. En $1546^{13}$ propuso su fundación a varios personajes ilustres de la ciudad ${ }^{14}$.

Los primeros jesuitas llegaron a Zaragoza en el verano de 1547 para preparar y poner en marcha el colegio que deseaba Borja. Parece ser que fueron acogidos en la casa palacio que el conservador del real patrimonio de Aragón y secretario de Carlos V, don Juan González de Villasimpliz tenía en el coso cerca del Arco de San Roque (Ferrer Benimeli, 2011) ${ }^{15}$, quien les hizo donación de una casa y hacienda para fundar el colegio. Donación que resultó muy conflictiva pues al morir el donante en 1548, sus hijos entablaron una serie de pleitos que obligaron a renunciar al proyectado colegio, a pesar de que personalmente lo había aceptado Ignacio de Loyola en vida del fundador don Juan González de Villasimpliz ${ }^{16}$.

13 Francisco de Borja, duque de Gandía, era hijo de don Juan de Borja y de la duquesa doña Juana de Aragón, hija del arzobispo de Zaragoza, don Alonso de Aragón, hijo del rey católico. Por lo tanto, la madre de Francisco de Borja era hermana del entonces arzobispo de Zaragoza don Hernando de Aragón. Ese mismo año de 1546, a raíz de la muerte de su esposa (el 27 de marzo), Francisco de Borja decidió entrar en la Compañía de Jesús y así lo hizo en secreto el 2 de junio. Dos años más tarde (1 febrero 1548) hacía la profesión solemne que le unía definitivamente a la Compañía. Pero mientras arreglaba los asuntos familiares (tenía ocho hijos a los que en 1543 - al morir su padre — se le añadieron otros ocho) y políticos mantuvo el secreto y siguió llevando su vida familiar y cortesana. Hasta 1551 no pidió permiso al emperador Carlos V para abandonar la Corte y dedicarse a su nueva vida. Permiso que le fue concedido. Ese mismo año fue ordenado de sacerdote y se integró de lleno en la vida religiosa.

${ }_{14}$ A los que envió varias cartas aprovechando el viaje del Dr. Miguel de Torres, que, después de visitarle en Gandía, pensaba pasar a Zaragoza.

15 En el siglo XVII pasó a pertenecer a los marqueses de Camarasa y después a los Condes de Fuentes, frente a la parte de la muralla vieja, en donde se abrió el Trenque de Jimeno Gordo, hoy calle Alfonso, donde el 27 de diciembre de 1737 nacería San José Pignatelli.

16 Juan González de Villasimpliz, habiendo enviudado y ordenado de sacerdote en 1531 fundó un colegio de doncellas o vírgenes. Para ello destinó una casa que tenía en el barrio de la morería, muy cerca de la suya propia. Consiguió del papa 
Posteriormente hubo otros intentos que también fracasaron, esta vez por la oposición de otras órdenes religiosas en función del privilegio de las "canas" concedido por la Curia romana a las órdenes mendicantes, por el que se prohibía la edificación de otra casa religiosa a menos de 300 canas de distancia —unos 147 metros - de los conventos ya edificados ${ }^{17}$, pues como

la bula fundacional y del concejo que por aquella parte del Coso --donde en su día estuvo el Arco de San Roque-, se abriera una comunicación con su convento de vírgenes ["Que se abra la calle de la Morería Cerrada al Coso, para dar comunicación al monasterio de las Vírgenes con el Coso. A súplica de la Emperatriz". Actas de 1534]. Pero al no tener éxito dicha fundación, en la que había colocado de superiora a su hija doña Ana, la deshizo con autoridad apostólica y ofreció esa casa y hacienda a los jesuitas para que establecieran allá su colegio. También les concedió una pequeña iglesia que se había aplicado a su colegio de vírgenes. En el verano de 1547 San Ignacio aceptó la oferta. Pero a principios de 1548 murió mosén Juan González de Villasimpliz, y su hijo Juan Luis movió pleito contra la Compañía con la ayuda de su hermana Ana y puso embargo alegando derechos que decía ser suyos. A pesar del apoyo a la Compañía de la otra hermana, doña Aldonza que deseaba se cumplieran los deseos de su padre, en el verano de 1548 llegó de Roma — de Ignacio de Loyolala orden de que los jesuitas entregaran la casa y demás y se retiraran de Zaragoza. Restaurado el colegio de Vírgenes [destinado a solteras y viudas hidalgas sin voto ni clausura] acabó ubicándose en 1585, en la todavía hoy llamada calle de las Vírgenes, muy próxima a la calle Contamina, entre Méndez Núñez y Jusepe Martínez. La casa que había albergado el colegio de los jesuitas pasó después a las madres Carmelitas descalzas; en 1594 a las Recogidas. Posteriormente a los Capuchinos y Agustinos descalzos. Finalmente se estableció en ese lugar una especie de "hospicio de religiosos" con el nombre de colegio de la Mantería, de agustinos observantes. Hoy es colegio de las Escolapias (Ximénez de Embún y Val, 1901, pp. 105-106; Jiménez Catalán y Sinués y Urbiola, 1924, pp. 283-284; March, 1935, t. I, pp. 3-4). De este primer pleito de los jesuitas de Zaragoza con los hijos de D. Juan González de Villasimpliz existen versiones que difieren en algunos detalles, aunque coincidentes en lo fundamental. Para unos el pleito se inició a la muerte del donante (Astrain, 1902, I, 438-441). Para otros se inició ya en vida y duró seis años. El que ofrece una descripción más completa del mismo es Azcona (2002, pp. 57-69), quien dice que el fundador, mentor espiritual, visitador y padre de las tres primeras colegiales - Ana, Isabel y Aldonza- les hizo donación para el nuevo Colegio de Vírgenes, «de un sector de su casa principal, que daba al Coso y a los huertos del convento de San Francisco». Se componía «de vivienda espaciosa, un corredor grande sobre la huerta, cenadores, azotea y caballeriza, así como de un pedazo de huerto que antes era çafareix [alberca] de las dichas mis casas», p. 58.

17 La cana era una medida equivalente, con corta diferencia, a dos varas o seis pies u ocho cuartas o palmos. Se usaba sobre todo en los territorios de la Corona de Aragón y otras partes. Era variable según los lugares. Reducida al sistema métrico decimal, una cana equivalía a 1,54 mts. en Zaragoza, 1,44 en Huesca, 1,53 en Teruel, 1,55 en Barcelona, 1,56 en Tarragona, 1,564 en Mallorca, 2,027 en Marsella, 2,4808 en Génova, 2,3345 en Toscana, etc. El privilegio de las canas, concedido por primera vez por Clemente IV en 1265, fue derogado por el papa Pío IV, por la bula Etsi ex 
el normal sustento de sus religiosos venía cubierto por las limosnas, así se protegía esta fuente de ingresos. Razón por la que los colegios de jesuitas - a diferencia de los mendicantes - debían estar "fundados», es decir, disponer de un capital - entregado por el fundador o fundadores-y de cuya renta se edificaría el colegio y se alimentarían los que en él vivieran y trabajaran.

La aprobación pontificia de los jesuitas suponía la posibilidad de edificar sus casas y colegios donde mejor pareciera. Las palabras de Julio III eran tajantes: Scholarium habere Collegiae, ubicumque ad ea construenda et dotanda ex devotione aliqui movebuntur ${ }^{18}$, aunque entraban en contradicción con el privilegio de las canas, lo que fue origen de no pocos conflictos, tanto más que los fundadores de los nuevos colegios de los jesuitas no sólo debían alimentar a sus miembros, sino edificar de planta los edificios con lo que directa o indirectamente los otros conventos perdían grandes cantidades de dinero. Era, pues, lógico que defendieran sus intereses. Pero la Compañía era también consciente de que si renunciaba a su privilegio papal se condenaba a no poder edificar en ninguna gran ciudad. En Zaragoza, según Gaspar Barreiros en su Corografía de algunos lugares que están en el camino, publicado en Roma en 1574, dice que en Zaragoza había 17 parroquias y 14 monasterios (nueve de frailes y cinco de monjas). Sin embargo, Juan Bautista Labaña, unos años después, en 1610 afirma que eran 14 las parroquias y 20 los monasterios, aparte de una iglesia colegial y cuatro colegios.

En el origen del colegio de Zaragoza, además del problema económico, habría que señalar otro de carácter sociológico, derivado del apoyo que las clases acomodadas de la ciudad prestaron a la Compañía. No era ningún secreto que el mayor impulsor del colegio zaragozano, Francisco de Borja, todavía duque de Gandía tenía gran influjo en la Corte, como consejero de Carlos V y de su esposa la emperatriz Isabel, cuyo cadáver fue encargado de llevar a la capilla real de Granada, en mayo de 1539, dos meses antes de ser nombrado virrey de Cataluña (1539-1543) (Dalmases, 2002). Resultaba, pues, lógico que los amigos del duque lo fueran también —o aparentaran serlo- de la nueva Orden. Frente a este apoyo de la nobleza y caballeros era previsible la reacción del estamento popular y sencillo en apoyo de los otros religiosos, que eran con los que hasta entonces habían vivido y tratado en sus respectivos barrios. Hubo, pues, partidarios de unos y otros.

Pero todavía existió un tercer factor, no menos grave, aparte del económico y sociológico. Este fue el religioso, como insinúa Antoni Borrás en su estudio sobre la fundación del colegio de Zaragoza (Borrás y Feliú, 1984,

debita del 13 de abril de 1561 que fue reiterada por Gregorio XIII en la Salvatoris mundi del 30 de octubre 1576. Previamente las 300 canas se habían reducido a 140.

18 Bula Exposcit debitum, 21 julio 1550. 
pp. 167-187). La recién nacida Compañía de Jesús se había convertido en uno de los protagonistas de la contrarreforma tridentina. Recordemos que cuando en 1546 se inician los trámites de la fundación del colegio de Zaragoza, el concilio de Trento (1545-1563) estaba ya en marcha. Y las intervenciones de Laínez y Salmerón (dos de los fundadores de la Orden) como teólogos pontificios, y en especial su decidida oposición a algunas doctrinas defendidas por la escuela agustiniana no podían pasar desapercibidas. Tal vez fue por eso que los agustinos de Zaragoza no deseaban tener por vecinos a quienes no compartían sus doctrinas teológicas. Las decisiones del concilio de Trento que exigían una profunda renovación de la vida religiosa y de las costumbres populares, en parte coincidía con las ya adoptadas por los jesuitas ${ }^{19}$. En este enfrentamiento entre lo nuevo y lo antiguo sólo los dominicos y los jerónimos apoyaron a los jesuitas de Zaragoza ${ }^{20}$.

Al fallar la donación de don Juan González de Villasimpliz los jesuitas que ya habían llegado a Zaragoza y obtenido el beneplácito verbal del arzobispo don Fernando de Aragón ${ }^{21}$, acabaron alquilando una pequeña casa en las cercanías de la parroquia de San Gil «en la morería que llaman cerrada», en la que abrieron una pequeña capilla privada y donde permanecerían año y medio gracias a la ayuda de «personas principales» ${ }^{22}$. Para poder vivir y soslayar posibles inconvenientes, los jesuitas no recibían ni recogían limosnas, sino que lo hacía por ellos don Jaime López quien asimismo las administraba. A estas había que añadir las 40 libras anuales que envió durante los primeros años el propio duque de Gandía, Francisco de Borja.

La búsqueda de un lugar definitivo para la ubicación del colegio resultó complicada. Se pensó en una casa que se hallaba «en la plaza que dicen

19 Insistencia en la frecuencia de los sacramentos, la discrección de espíritus según las Reglas de los Ejercicios, las doctrinas sobre la justificación...

${ }_{20}$ Los dominicos, que tenían su primer convento en la plaza de Santo Domingo, al final de la calle Predicadores, en el lugar que hoy ocupa la Casa Amparo. Los Jerónimos habitaban el monasterio de Santa Engracia, destruido en la guerra de Independencia.

21 D. Hernando de Aragón (1498-1575) cisterciense, se ordenó de sacerdote en 1524 en el Monasterio de Piedra. Después fue Abad del de Veruela. Nombrado arzobispo de Zaragoza en 1539 continuó viviendo en Veruela hasta 1541. Era hijo del anterior arzobispo de Zaragoza, D. Alonso de Aragón, y hermano de la madre de Francisco de Borja, doña Juana de Aragón casada con el duque don Juan de Borja. Sin embargo, sus relaciones con los jesuitas de Zaragoza fueron poco cordiales.

22 Don Miguel Clemente, protonotario del Consejo Real de Aragón; don Gonzalo Paternoy, Maestre racional; micer Jaime Agustín del Castillo; Mateo Morrano, Gobernador de la acequia real. El Maestre racional era uno de los cuatro oficiales entre los que se repartía el Gobierno de la casa y corte del rey, al que correspondía la administración del real patrimonio y la intervención general de los ingresos y gastos. 
de Meliz», en la parroquia de San Pablo, no lejos del convento del Carmen (Ansón Navarro, 2007) ${ }^{23}$. Los carmelitas no sólo visitaron a los jesuitas para exponerles los inconvenientes que se seguirían de asentarse en esa casa, temerosos de perder buena parte de las limosnas que recibían, sino que movieron el descontento de la gente. Esto llevó a buscar un nuevo lugar en el coso entre el hospital general y de Ntra. Señora de Gracia y Santa Catalina $^{24}$. Pero tanto las monjas clarisas del convento de Santa Catalina, como los padres franciscanos se opusieron, siendo en esta ocasión no pequeño el alboroto que se movió, tanto más que en dicho convento de las clarisas era monja una sobrina del arzobispo quien estaba sufragando importantes reformas.

De nuevo se optó por la renuncia. Entonces hubo opción de poder comprar un patio y casas viejas propiedad de Juan de Torrelles en la calle «que dicen de los cides, junto al callizo llamado de la traición ${ }^{25}$. Pero los clérigos de la parroquia de Nuestra Señora del Pilar y los de San Felipe, ambas muy próximas al lugar ofrecido se opusieron con lo que se pensó abandonar el proyecto, pero el prior de los dominicos, fray Tomás Esquivel, había ya solventado la cuestión económica (1.000 libras) tras reunir en su convento a «los principales de la ciudad». Llevada a cabo la compra de estas casas, se ofreció la posibilidad de adquirir otra colindante. Pero esto provocó nuevamente la oposición de clérigos y religiosos. Nueva interrupción de las gestiones hasta que en la primavera de 1554 el nuevo provincial de Aragón, Francisco Estrada, vino a Zaragoza a intentar resolver de una vez la fundación del colegio que venía arrastrándose desde hacía años. Ante la

${ }^{23}$ Sobre la llegada de los carmelitas a Zaragoza y la construcción y vida de sus diferentes domicilios, especialmente el conocido como convento del Carmen ubicado en plena morería entre lo que hoy es la plaza del Carmen y la Puerta de Baltax o del Carmen en lo que había sido parte del fosal árabe. No lejos de la plaza del Carmen estaba la plaza de Meliz o Melik, hoy plaza San Lamberto. La parroquia de San Pablo en aquel entonces era la que mayor territorio abarcaba, llegando desde el Ebro y plaza de Santo Domingo hasta el Portillo por un lado y al muro de rejola hasta más allá de la Puerta del Carmen por el otro hasta cerca del monasterio de Santa Engracia.

${ }^{24}$ La iglesia y hospital de Nuestra Señora de Gracia, con sus huertas y dependencias ocupaban una gran manzana limitada por el norte con el Coso a partir del humilladero Cruz del Coso y Puerta Cinegia [enfrente del "Tubo"] hasta más o menos la actual calle de Porcell, paralela a la de Santa Catalina. Y por el sur llegaba hasta la actual calle de San Miguel, cerrando el rectángulo lo que hoy es Plaza de España y paseo de Independencia y casas colindantes (Ibañez Fernández, 2000, pp. 141-152).

25 Ya en 1440 tenía este nombre. En ella fue muerto hacia el año 1610 D. Juan Coloma. Actualmente se llama calle de Atarés. 
imposibilidad de conseguir la casa adjunta a las ya adquiridas para colegio, aconsejaron al provincial vender lo ya comprado -como así hicieron- ${ }^{26}$ y buscar otro lugar más amplio.

Se decidieron por unas casas que, aunque en estado ruinoso, disponían de un gran solar, y que acabaría siendo el lugar definitivo ${ }^{27}$. Estaban no lejos de la parroquia de la Magdalena, enfrente de la Casa de los Morlanes, en pleno barrio judío, donde había estado ubicada la Sinagoga mayor, el hospital y el castillo de los judíos [o cárcel de las siete torres] derribados en 1528. También abarcaban el antiguo postigo del Rabinado o Portal de la Judería también demolido en 1500 y con él las casas de las carnicerías de los judíos allí existentes $^{28}$. Su precio era de 2.500 libras, firmándose el contrato de compra la vigilia de Navidad de aquel año de $1554^{29}$.

El provincial informó personalmente al nuevo virrey Pedro Martínez de Luna, duque de Francavila, quien convocó a doscientos caballeros de la ciudad, que decidieron ayudar. El Jurado mayor que estaba sentado junto al virrey no quiso que la ciudad quedara al margen y pidió al provincial que hablara también a los jurados y consejeros de la ciudad, como así hizo en la lonja donde solían tener sus ayuntamientos. Como resultado de ambas pláticas dos caballeros se encargaron de recoger limosnas por la ciudad que ascendieron a 4.000 escudos. Resueltos los problemas económicos se fijó la fecha del 17 de abril para la fundación canónica del colegio. Para ello se contó con el amigo incondicional de los jesuitas de Zaragoza, el prior de los dominicos, fray Tomás Esquivel, quien presidiría el acto, y como predicador el padre jerónimo Juan Azolora, del monasterio de Santa Engracia.

Habían pasado siete años desde la llegada de los jesuitas a Zaragoza en 1547, y tras elegir siete lugares diferentes, finalmente encontraron el que creían más idóneo y menos conflictivo.

26 María Sánchez de Toledo, mujer del vendedor se ofreció a recomprarla por el mismo precio. También fue muy complicada la fundación del colegio de San Sebastián (Tellechea Idígoras, 1997).

27 Fue D. Diego Morlanes, abogado zaragozano, quien las compró para la Compañía. Por ellas pagó 400 ducados e hizo la donación el 21 de agosto de 1557. Estas casas, incluidos el corral y huerto, pertenecían a Sancho de Francia y confrontaban con otras de Juan de Alfajarín y las de los herederos de Tomás Cornel con los graneros de la ciudad y con el Coso (Ximénez de Embún y Val, 1901, p. 63).

28 Hoy calle Santo Dominguito del Val.

29 La libra era moneda convencional de cuenta equivalente a un escudo (22 quilates) o 20 sueldos. El ducado (23,3 quilates) equivalía a 22 sueldos. El oro puro tenía 24 quilates. Quilate = unidad que sirve para designar la pureza del oro en una aleación. 
Pero la víspera, los agustinos, basándose en el privilegio de las canas, impugnaron el acto por medio del Vicario General, don Lope Marco, abad de Veruela. Ante el temor de desairar al virrey y nobleza que habían sido invitados, se optó por la inauguración. Y cuando ya estaban los oficiantes revestidos en la sacristía de la recién arreglada capilla para la misa solemne, se presentó el padre guardián de los franciscanos quien, en nombre de los agustinos, que le habían nombrado juez conservador, exigió suspender el acto $^{30}$. A pesar de ello se decidió continuar con la ceremonia de inauguración y una vez celebrada la misa solemne se encontraron con la sorpresa de hallar pegado en las paredes exteriores de la capilla un edicto del Vicario General condenando lo realizado y amenazando de excomunión a cuantos se atrevieran a asistir o participar en cualquier acto religioso en esa capilla. Decreto que dió orden a todos los rectores y vicarios lo publicasen también en sus iglesias ${ }^{31}$.

A partir de este momento la situación se complicó todavía más. Los agustinos entablaron juicio canónico basándose en el privilegio de las canas por el que pretendían que no se podía hacer casa de religión ni iglesia dentro de las 300 canas de su convento. Los párrocos de la Magdalena y de San Miguel, también próximos al lugar elegido por los jesuitas para su nuevo colegio, acudieron al Justicia pidiéndole que les mandase salir y les prohibiese la construcción del colegio e iglesia. Al mismo tiempo le rogaron que pusiese las armas de Aragón pintadas en papeles en las paredes de las casas adquiridas por los jesuitas. De esta forma, mientras el Justicia no pronunciara sentencia no podrían hacerse obras.

Ante esta situación y a la vista de que el Vicario General — por orden del arzobispo- se negó a revocar el edicto contra los jesuitas, estos acudieron al virrey, duque de Francavila — que había estado presente en el acto de posesión- y además eligieron juez conservador al obispo de Huesca, don Pedro Agustín, que tenía jurisdicción sobre una parte importante del Zaragoza extra muros.

El 23 de junio el juez conservador de los agustinos mandó publicar en todas las iglesias y monasterios de la ciudad la excomunión de todos los

30 El "juez conservador" era una figura jurídica entonces existente para dirimir pleitos entre eclesiásticos sin tener que recurrir a la justicia civil. Otro tanto había ocurrido en 1552 cuando el entonces obispo de Valencia [Santo Tomás de Villanueva] salió en defensa de los jesuitas contra los agustinos que querían impedir la construcción del colegio de Valencia.

31 El arzobispo y vicario se reservaban la absolución, previo juramento de no acudir en adelante a la capilla de los jesuitas. Poco después extendieron esa facultad a algunos vicarios de las parroquias. 
jesuitas de Zaragoza. A su vez el juez conservador de los jesuitas hizo otro tanto contra el guardián de los franciscanos, los frailes de San Agustín y los clérigos de la Magdalena y de San Miguel, pero solo la pudo hacer pública en el monasterio de su jurisdicción, ya que las colocadas por la ciudad fueron inmediatamente arrancadas. El paso siguiente fue poner en entredicho a los jesuitas, con lo que no podían ejercer el culto en su capilla. Al entredicho y mutuas excomuniones y enfrentamientos jurídicos, se añadieron algaradas callejeras, procesiones penitenciales organizadas por los agustinos contra la Compañía ${ }^{32}$, apedreamiento del colegio por grupos de muchachos, etc. (Astrain, 1902, pp. 448 y ss).

El último recurso de los jesuitas fue acudir a la Corte y a Francisco de Borja. En aquellos días Felipe II se encontraba en Inglaterra para casarse con María Tudor, hija de Enrique VIII y Catalina de Aragón. La hermana de Felipe, la princesa doña Juana, dirigida espiritualmente por Francisco de Borja $^{33}$, era, con 19 años, la Regente de España ${ }^{34}$, y desde el 3 de enero de 1555, era también miembro de la Compañía de Jesús (Villacorta Baños, 2005; Dalmases, 2002, pp. 119-121 $)^{35}$.

32 "Concitó también mucho al pueblo una demostración lúgubre que hicieron los frailes de San Agustín y algunos clérigos de las parroquias, y fue que a 26 de julio, en las vísperas cantaron el salmo 108, o, como entonces se decía, el salmo de la maldición, y después salieron procesionalmente, con un crucifijo cubierto de velo negro, hacia nuestro colegio, repitiendo el mismo salmo y echando piedras hacia atrás, ceremonia que entonces se usaba para detestar y condenar a los excomulgados... Los frailes de San Agustín iban por las calles alrededor de nuestro colegio diciendo a voces: Misericordia, misericordia. Archivo de Simancas, Estado, leg. 318. Citado por (Astrain, 1902, p. 451). El convento de los agustinos, hoy Centro de Historia de la ciudad de Zaragoza, había sido propiedad de los franciscanos quienes lo abandonaron a principios del siglo XIV.

33 Francisco de Borja había hecho la profesión solemne en la Compañía el 1 de febrero de 1548, después de asistir a las Cortes aragonesas de Monzón, celebradas en 1547, a las que le envió Felipe II. Sobre el ingreso de Borja en la Compañía, cfr. Dalmases, 69-74.

${ }^{34}$ Casada con su primo hermano don Juan Manuel de Portugal (11 de enero 1552) a los 17 años, enviudó poco después, el 2 de enero de 1554, al morir su marido de tuberculosis. El 20 de enero nacía su hijo póstumo. A petición de su padre, Carlos V, que tenía intención de abdicar (lo haría el 28 septiembre 1556 retirándose al monasterio de Yuste donde murió en 1558) regresó a España el 17 de mayo 1554. El 12 de julio asumió la regencia ante la ausencia del Emperador y de su hijo y sucesor al trono, Felipe II. Regencia que duró hasta 1559 en que Felipe II volvió definitivamente a España.

35 Otro caso también extraño y extraordinario de una mujer jesuita fue el de Mary Ward (Javierre, 2002). Con ella se cerró el ciclo de mujeres jesuitas, iniciado con la barcelonesa Isabel Roser y sus dos compañeras que consiguieron del papa la 
El 25 de junio de 1555 intervino por primera vez la Regente en el asunto del colegio de Zaragoza, escribiendo cartas al virrey de Aragón, al arzobispo de Zaragoza, al abad de Veruela, al obispo de Huesca y al Justicia de Aragón, cartas que apenas produjeron efecto, tal vez por desconocimiento de la personalidad de la joven Regente, que reaccionó enviando a la ciudad un rey de armas para que pusiera en el colegio las armas de la corona, aunque no pudo lograr que el Vicario General y Abad de Veruela revocara el edicto condenatorio.

Los jesuitas decidieron entonces abandonar la ciudad, previa entrega de las llaves del colegio a la Casa de la Ciudad, pidiendo se inventariara su contenido. El 1 de agosto se acogieron al ofrecimiento que la hermana de Francisco de Borja, doña Luisa de Aragón y de Borja les hizo de su casa-palacio de Pedrola «a siete millas de la ciudad» ${ }^{36}$. Entretanto el P. Tablares se dirigió a Valladolid —donde ya se encontraba el P. Román- para informar a la Corte de los últimos acontecimientos.

Con la salida de los jesuitas se levantó el entredicho de la ciudad y los ánimos se serenaron un tanto. De hecho, el mismo día que el P. Tablares entregaba las llaves del colegio a la ciudad, escribía la Regente la segunda serie de cartas a las autoridades zaragozanas ${ }^{37}$. En ellas se mandaba que en el plazo de quince días se personaran en la Corte el abad de Veruela, el guardián de San Francisco, el prior de San Agustín, el rector de San Miguel y el vicario de la Magdalena. Estas cartas lógicamente llegaron a Zaragoza cuando los jesuitas ya la habían abandonado ${ }^{38}$.

Finalmente, el 8 de septiembre el Vicario General revocó el edicto de condena y pidió en su nombre y en el del arzobispo el regreso de los jesuitas que se fijó para el día siguiente. Fueron recibidos en el monasterio de Trinitarios de San Lamberto por «muchos caballeros y gente principal» quienes los acompañaron hasta la puerta del Portillo. Allí les esperaban el Obispo de

autorización para hacer la profesión solemne de la Compañía. La experiencia fracasó e Ignacio consiguió un breve pontificio fechado el 25 de junio de 1547, por el que la Compañía quedaba libre del compromiso adquirido. Juana de Austria ocultó su identidad en la correspondencia jesuítica bajo el nombre de Mateo Sánchez.

36 Luisa de Aragón y Borja, hermana de Francisco de Borja, estaba casada con Martín, conde de Gurrea, duque de Luna y $4^{\circ}$ duque de Villahermosa desde 1558.

37 Cfr. varios y extensos fragmentos, tomados del Archivo de Simancas (Astrain, 1902, pp. 456-458).

38 El abad de Veruela envió a la Corte a dos agentes suyos para que le defendieran en presencia de doña Juana. También el arzobispo mandó a Valladolid al doctor Espes. Pero la princesa-regente se negó a darles audiencia, exigiendo que se presentara el vicario-abad en persona. 
Huesca y el Vicario General-Abad de Veruela, el Justicia de Aragón, Jurados y otra mucha gente. Formada la comitiva ${ }^{39}$ se dirigieron todos hasta el colegio donde les aguardaban el virrey y uno de los Inquisidores ${ }^{40}$, así como mucha gente. Trasladados a la capilla, el obispo de Huesca celebró la misa del Espíritu Santo, y, ésta acabada, el propio obispo y el Jurado Mayor dieron a los recién venidos posesión de sus casas.

Con el regreso y aceptación oficial de los jesuitas pudo procederse a la adquisición de nuevas casas colindantes, entre ellas la que había sido Sinagoga y que entonces servía de granero. Fué acondicionada y consagrada iglesia en 1557 con el título de Nuestra Señora de Belén, por don Pedro Agustín, obispo de Huesca, Jaca y Barbastro que constituía un sólo obispado. Presidió la ceremonia el provincial P. Francisco Estrada y predicó el viceprovincial P. Bautista Barma. En 1559 se encargó un retablo presidido por «la historia del Nascimiento de Christo», en sintonía con la advocación de Nuestra Señora de Belén.

Las obras del definitivo edificio del colegio no se iniciaron hasta 1567. Y dos años después, el 13 de abril de 1569, habiéndose quedado pequeña la primitiva iglesia-sinagoga se empezó, en el mismo lugar, la construcción de un nuevo templo, colocándose la primera piedra el 23 de marzo, festividad de San Jorge, oficiando fray Antonio García, obispo de Útica y auxiliar del arzobispo don Hernando de Aragón. Las obras duraron hasta 1585. La consagración tuvo lugar el domingo 24 de noviembre y se dedicó a la Inmaculada Concepción ${ }^{41}$. Y el colegio recibió el nombre de la Purísima Concepción de Nuestra Señora (Arbizu, s.f., p. 152), más conocido en su época como Colegio grande de los jesuitas. En ambos casos parece se siguió la traza del plano

39 La comitiva la formaban en primer lugar el P. Román, flanqueado por Don Juan de Lanuza, Justicia de Aragón, y micer Jaime Agustín, Jurado mayor. Con el P. Santander iban Don Juan Luis González, Conservador de Aragón, y Don Gonzalo Paternoy, Maestro racional de Aragón. Al P. Piñal acompañaban el Jurado segundo y el Justicia ordinario de Zaragoza. Seguían los demás jesuitas, caballeros y autoridades, todos a caballo. Era entonces Justicia de Aragón Juan de Lanuza IV el Viejo que murió el 22 de noviembre de 1591, sucediéndole Juan de Lanuza "el Mozo" o "el Joven" quien un mes después sería ajusticiado por orden de Felipe II el 20 de diciembre de 1591, cerrándose así la saga de los cinco Justicias que llevaron el nombre de Juan Lanuza.

$40 \mathrm{Al}$ apearse todos a la puerta del colegio, el abad de Veruela abrazó a los jesuitas, dándoles el parabién por su venida. La ausencia del arzobispo hace sospechar a Astrain que el origen de la animadversión anterior no estaba tanto en el Vicario sino en el arzobispo, actuando el Vicario al dictamen de aquel (Astrain, 1902, p. 462).

${ }^{41}$ Cfr. «La llegada y el establecimiento de los jesuitas en Zaragoza» (Zamora, Criado Mainar, Ibáñez Fernández, Mendoza Maeztu, 2010, pp. 123-145). 
conservado en la Biblioteca Nacional de París (Boloqui Larraya, 2010, p. 68; Ibáñez Fernández, 2005, p. 248 ${ }^{42}$.

En un intento de ampliación de las funciones educativas del colegio y abrirlo a la universidad, obtuvieron de Pío IV, en 1562, autorización para fundar Escuelas de Gramática y Latinidad, si bien la del Concejo y la del arzobispo no llegaron hasta $1579^{43}$. Escuelas que fueron origen de nuevos enfrentamientos, esta vez con el Consejo y el Estudio Mayor, convertido poco después en Universidad. Pues estas escuelas tenían rango universitario y sus cursos eran obligatorios para todos los que querían entrar en la Universidad, razón por la que tenían una doble jurisdicción: la jesuítica (académica) y la universitaria (de control y disciplina). Dichas escuelas se ubicaron, al igual que el colegio del Padre Eterno (que era un convictorio para estudiantes) a continuación del colegio en la parte colindante al $\mathrm{Coso}^{44}$. Un arco volado sobre la calle Nueva o de San Jorge, tendido en 1613, unía el colegio con las aulas de gramática.

En 1564, de los 20 jesuitas que había en el colegio «fueron heridos de la peste y murieron seis» (Arbizu, s.f., III, p. 33). Cien años después, en 1652, se declaró de nuevo la peste y el Colegio fue convertido en «morbería» y de nuevo hubo bajas entre los doce de la comunidad que se dedicaron de lleno a cuidar a los apestados (Arbizu, s.f., pp. 34-46). En 1574 había en el colegio 34 jesuitas y en 1600 - transcurridos los primeros cincuenta años de presencia en Zaragoza-, eran 45, y el colegio había consolidado su posición ${ }^{45}$.

${ }^{42}$ Cfr. También (Zamora, Criado Mainar, Ibáñez Fernández, Mendoza Maeztu, 2010, p. 137).

43 "El arzobispo de Zaragoza y la ciudad piden a la Compañía se encargue de las escuelas de latinidad y parece que conviene aceptarlas pues además del provecho que recibirán los estudiantes y servicio al Sr. Arzobispo y ciudad tiene la Compañía obligación de ponellas por los beneficios que aquel colegio tiene unidos". Citado por Bartolomé Martínez (1982, p. 403).

${ }^{44}$ Los planos (plantas y alzado) de ambos edificios se conservan en el Archivo de Simancas y están reproducidos en El plano más antiguo de Zaragoza, 151, 153 y 155. El colegio-convictorio del Padre Eterno se pudo construir con el patronazgo del secretario real Jerónimo Villanueva. En el momento de la expulsión funcionaba como Casa de Tercera Probación y residían en él 10 jesuitas que unidos a los 53 del colegio grande o de la Purísima hacían un total de 63. Con la expulsión quedó convertido en Seminario Conciliar a cargo de los individuos del Seminario Sacerdotal de San Carlos. Las escuelas de gramática siguieron funcionando como tales, pero el segundo piso del edificio que se había convertido en Casa de Ejercicios de San Ignacio se habilitó para «habitación de los maestros».

45 A lo largo del siglo XVI fallecieron en Zaragoza 39 jesuitas (Fernández Marco, 2011, pp. 47-48). 
En 1732 llegaron los escolapios a Zaragoza ${ }^{46}$ y obtenida licencia para abrir escuelas de primeras letras, añadieron otras de gramática, iniciándose un pleito con los jesuitas a quien las Concordias con la Universidad de los años 1609 y 1628 les habían concedido en exclusiva dicha enseñanza. Pleito que llevó a la intervención del Consejo de Castilla que ordenó el cierre de las aulas de gramática de los escolapios ${ }^{47}$.

En 1767, en el momento de la expulsión, los jesuitas que atendían los dos colegios de Zaragoza y las escuelas de gramática y latinidad eran 63, entre ellos José Pignatelli cuya vida estuvo siempre muy vinculada al colegio de Zaragoza, como estudiante siendo niño —al igual que su hermano Nicolásdespués cursando teología y en el momento de la expulsión enseñando letras a los más pequeños (Ferrer Benimeli, 2011).

A raíz de la expulsión y quedar sin uso la iglesia y el colegio, Carlos III pidió informes sobre el destino y aplicación que se les podían dar. A la vista de ellos, mandó el 21 de agosto de 1769 que el Colegio grande o principal y su iglesia — «que había sido de la Compañía» - se aplicaran al Seminario sacerdotal de San Carlos Borromeo, fundado el 12 de abril de 1737 y que tenía su sede en la plazuela del Reino (Ferrer Benimeli, 2011) ${ }^{48}$. El auto de traslación lleva la fecha del 31 de enero de 1770 y en él se acuerda que la iglesia de la Compañía se denomine en lo sucesivo "Iglesia Real de la Concepción», y el colegio "Seminario Real de San Carlos», previa sustitución en ambos edificios del escudo de los jesuitas por el de armas del rey Carlos III (Calvo Guinda, 1988, pp. 423-424).

En el momento de la expulsión (1767) la Asistencia jesuítica de España contaba con cerca de 5.000 jesuitas -más exactamente 4.995-: 2.727 en la metrópoli y 2.267 en América y Filipinas. Sólo en la metrópoli tenían 132 colegios, sin contar los de ultramar que eran otros 101, más 31 seminarios.

Unos años más tarde, en 1749 apenas 24 años antes de que la Compañía fuera extinguida por el Papa Clemente XIV, el número de jesuitas en todo el mundo era de 22.589 y tenía o regentaba 840 centros de educación: 669 colegios y 176 seminarios $^{49}$. Poco después, entre 1759 y 1767, se perdieron 411 de estos colegios a raíz de la expulsión de los jesuitas de Portugal, Francia y

46 La Orden fundada por San José de Calasanz (1557-1648) oriundo de Peralta de la Sal (Huesca) se introdujo en Aragón a partir de Barbastro (1677), Benabarre (1681), Peralta (1695), Daroca (1728), Alcañiz (1729), Zaragoza (1732), Albarracín (1732), Jaca (1735), Tamarite (1741).

47 Otro tanto ocurrió en Valencia (Bartolomé Martínez, 1982, pp. 423-424).

48 Hoy San Vicente de Paúl a la altura del palacio de Palafox.

49 Estos datos corresponden al último catálogo general de la Compañía que existe antes de la disolución, con lo que tenemos un vacío de información de 24 años (Hamy, 1893; Lamalle, 1944, pp. 77-101). 
España: 58 en la Asistencia de Portugal (21 en Portugal, 9 en Azores, Madeira y Africa oriental), 233 en la Asistencia de España (132 en la metrópoli y 101 en América y Filipinas ${ }^{50}$ y 120 sólo en la Francia metropolitana.

William V. Bangert, de la St. Louis University de Missouri, en la edición de 1972 de su A History of the Society of Jesus, consciente de su exageración, hace un símil entre la Europa del siglo XII, convertida en un gran Cister, y el mundo católico de 1770 que llegó a ser un gran Colegio jesuítico.

El influjo social que consiguieron por medio de los colegios fue, segúramente, como afirma Revuelta, la clave profunda que explica las persecuciones (expulsiones y extinción) que sufrieron los jesuitas en la segunda mitad del siglo XVIII (Revuelta González, 1998, p. 2).

\section{REFERENCIAS}

Ansón Navarro, A. (2007). El entorno del convento del Carmen de Zaragoza. Una reconstrucción histórica y artística. Siglos XIII al XX. Zaragoza.

Astráin, A. (1902). Historia de la Compañia de Jesús en la Asistencia de España. Madrid: Razón y Fe.

Arbizu, J. Historia de el Colegio de la Compañia de Jesús de Zaragoza. Tercera Parte. Comienza desde el año 1650 hasta el de 1700 [manuscrito].

Azcona, T. (2002). El Colegio de las Vírgenes de Zaragoza en el siglo XVI. Memoria Ecclesiae, XX, 57-69.

Bartolomé Martínez, B. (1982). Las cátedras de gramática de los jesuitas en las universidades de Aragón. Hispania Sacra, XXXIV, 389-448.

Bertrán Quera, M. (1984). La pedagogía de los jesuitas en la Ratio Studiorum. San Cristóbal: Universidad del Táchira.

Boloqui Larraya, B. (2010). El colegio de la Compañía de Jesús en Zaragoza en el que vivió Baltasar Gracián. Apuntes para su historia desde su fundación (15701599). En Zaragoza en la Epoca de Baltasar Gracián. Zaragoza: Ayuntamiento de Zaragoza.

\begin{tabular}{|c|c|c|}
\hline 50 PAÍSES & Colegios & SEMINARIOS \\
\hline Argentina-Paraguay & 11 & \\
\hline Bolivia-Chile & 12 & 3 \\
\hline Centroamérica & 5 & 2 \\
\hline Colombia-Venezuela & 10 & 2 \\
\hline Ecuador & 11 & 2 \\
\hline Filipinas & 7 & 1 \\
\hline México & 29 & 14 \\
\hline Perú & 16 & 6 \\
\hline TOTAL & 101 & 31 \\
\hline
\end{tabular}


Borrás y Feliu, A. (1984). Fundación del Colegio de la Compañía de Jesús en Zaragoza. En La ciudad de Zaragoza en la Corona de Aragón (pp. 167-187). Zaragoza: Institución Fernando El Católico.

Calvo Guinda, F. J. (1988). El Real Seminario de San Carlos de Zaragoza. Sus orígenes (1737-1788). Zaragoza: Centro Regional de Estudios Teológicos.

Dainville, F. de, (1978). L'éducation des jésuites (XVIe-XVIIIe siècles). Paris: Les Editions de minuit-Institut national de recherche pédagogique.

Dalmases, C. (2002). El Padre Francisco de Borja. Madrid: BAC.

Farrell, A. P. (1937). Colleges for Extern Studens opened in the lifetime of Ignatius. Archivum Historicum S.I. VI, 287-291.

Fernández Marco, J. I. (2011). Notas históricas. Colegio de la Purísima (Zaragoza: 1547-1767). Bilbao: Mensajero.

Ferrer Benimeli, J. A. (2011). José Pignatelli (1737-1811). La cara humana de un santo. Bilbao: Mensajero.

Ferrer Benimeli, J. A. (1984). Les écoles des jesuites de la Province d'Autriche à l'âge des Lumières. En Les Lumières en Hongrie, en Europe centrale et en Europe orientale. Budapest: Akadémiai Kiadó.

Gil, E. (Ed.) (1992). El sistema educativo de la Compañía de Jesús. La Ratio Studiorum. Madrid: Universidad Pontificia Comillas.

Hamy, A. (1893). Documents pour servir à l'histoire des domiciles de la Compagnie de Jésus dans le monde entier (1540-1773). Paris: Picard.

Ibáñez Fernández, J. (2005). Arquitectura aragonesa del siglo XVI. Zaragoza: Fundación Fernando el Católico.

Ibañez Fernández, J. (2000). La cruz del Coso de Zaragoza, memoria artística de un monumento desaparecido. Boletín del Museo e Instituto Camón Aznar, XXX.

Iparraguirre, I. (1962). Pensamiento y actitud de San Ignacio de Loyola acerca de los colegios. Revista Calasancia, 30, 189-198.

Javierre, J. M. (2002). La Jesuita Mary Ward. Mujer rebelde que rompió moldes en la Europa del XVII. Madrid: Libroslibres.

Jiménez Catalán, M., y Sinués y Urbiola, J. (1924). Historia de la Real y Pontificia Universidad de Zaragoza. Zaragoza.

Labrador, C. et. al. (1986). La «Ratio Studiorum» de los jesuitas. Madrid: Universidad Pontificia Comillas, 1986.

Lamalle, E. (1944). Les catalogues des provinces et des domiciles de la Compagnie de Jésus. Archivum Historicum S.I., XIII, 77-101

Leturia, P. de (1957). La pedagogía humanista de San Ignacio y la España imperial de su época. Estudios Ignacianos, t. I, 323-354.

Leturia, P. de (1940). Perchè la Compagnia di Gesù divenne un ordine insegnante. Gregorianum, 350-382.

Luckacs, L. (1960-1961). De origine collegiorum externorum deque controversis circa eorum paupertatem obortis 1539-1608. Archivum Historicum S.I., XXIX, 189245; XXX, 3-89.

March, J. M. (1935). El restaurador de la Compañia de Jesús Beato José Pignatelli y su tiempo. Barcelona: Ibérica.

Marquis, A.-J. (1969). Le Collège Saint-Michel de Fribourg (Suisse). Sa fondation et ses débuts 1579-1597. Fribourg. 
Muñoz, J. (1960). La formación humanística según San Ignacio y la Compañía de Jesús. Humanidades, XI, 23, 1960, 203-244

Olaechea, R. (1976). El anticolegialismo del Gobierno de Carlos III. Cuadernos de Investigación, t. 2, fasc. 2, diciembre, 53-90.

Revuelta González, M. (1998). Los colegios de jesuitas y su tradición educativa (18681906), Madrid: Universiad Pontificia Comillas.

Revuelta González, M. (2001). La Compañía de Jesús en Aragón hace cien años. Miscelánea Comillas, 59, 191-209.

Sommervogel, C. (1890). Bibliothèque de la Compagnie de Jésus. Bruxelles, t. I, col. 223-249.

Tellechea Idígoras, J. I. (1997). Una historia turbulenta. La fundación de la Compañía de Jesús en San Sebastián (1619-1627). San Sebastián: Fundación Social y Cultural Kutxa.

Villacorta Baños, A. (2005). La jesuita: Juana de Austria. Barcelona: Ariel.

Ximénez de Embún y Val, T. (1901). Descripción histórica de la antigua Zaragoza y de sus términos municipales. Zaragoza: Cecilio Gasca.

Zamora, M. I., Criado Mainar, J. F., Ibáñez Fernández, J., y Mendoza Maeztu, N. (2010). El plano más antiguo de Zaragoza. Zaragoza: Institución Fernando el Católico. 